\title{
Pitanje stila i problemi periodizacije: nedovršeni posao povjesničara umjetnosti (2. dio)
}

\section{Milinović, Dino}

Source / Izvornik: Institucije povijesti umjetnosti : zbornik 4. kongresa hrvatskih povjesničara umjetnosti, 2019, 101 - 105

Conference paper / Rad u zborniku

Publication status / Verzija rada: Published version / Objavljena verzija rada (izdavačev PDF)

https://doi.org/10.31664/z4khpu.13

Permanent link / Trajna poveznica: https://urn.nsk.hr/urn:nbn:hr:254:455059

Rights / Prava: Attribution 4.0 International/Imenovanje 4.0 međunarodna

Download date / Datum preuzimanja: 2023-04-26

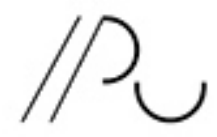

INSIITUTR ZA POVIJEST UMJETNOST
Repository / Repozitorij:

PODEST - Institute of Art History Repository

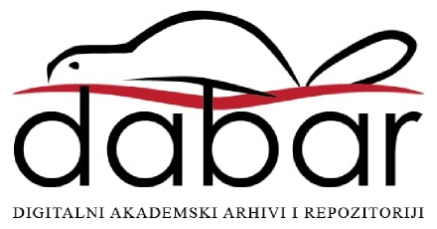




\section{Pitanje stila i problemi periodizacije: nedovršeni posao povjesničara umjetnosti (2. dio)}

Još su početkom 70-ih godina prošloga stoljeća Meyer Schapiro, Ernst Gombrich i Horst Waldemar Janson raspravljali o univerzalnosti pojma stila u povijesti umjetnosti. Sumnja u monopol formalne analize kao temeljne znanstvene metode, koju su već tada izrazili, može i danas iznenaditi. Naposljetku, studenti povijesti umjetnosti na Sveučilištu u Zagrebu generacijama su bili navikli smatrati Heinricha Wölfflina i njegove Osnove znanstvenim legitimitetom naše discipline. U srednjoj smo školi učili da je „način kako umjetnik vidi i prema tome prikazuje temu najvažniji element umjetničkog djela, njegovo uobličenje, ostvarenje u određenom materijalu, njegova forma". ${ }^{1}$ No može li formalna analiza (kako) biti shvaćena kao apsolutna vrijednost i je li kao metoda dostatan kriterij za uspostavu čvrste, linearno strukturirane povijesti umjetnosti?

Od Michela Foucaulta i pomalo zbunjujuće teorije postmodernizma mnogi dovode u pitanje okvire tradicionalne discipline. ${ }^{2}$ Razlozi da se vratim propitkivanju univerzalnosti stila dvostruki su: kao prvo, milenijska paradigma „kraja povijesti umjetnosti”, od koje se još oporavljamo, kao od mamurluka poslije razuzdane novogodišnje noći. Hans Belting, koji o toj temi piše u nekoliko navrata, ${ }^{3}$ opetovano propitkuje tradicionalni okvir povijesti umjetnosti: „Ideja samostalne discipline povijesti umjetnosti, s unutrašnjom strukturom i logikom, koja se razotkriva u izmjenama vremenskih stilova, jest iza nas: što se više urušava unutrašnje jedinstvo autonomno shvaćene discipline povijesti umjetnosti, to se više ona razvodnjava u širokom moru kulture i društva...". Ako smijem pojednostavniti Beltinga, linearni razvoj povijesti umjetnosti, shvaćen kao sukcesija stilova i stilskih razdoblja, pomogao je, doduše, stvoriti našu disciplinu, ali je s vremenom ujedno sputao mogućnosti promišljanja i shvaćanja mnoštva novih likovnih fenomena. Jednom načet, univerzalni kriterij stila možemo dovesti $u$ pitanje i na primjeru ranijih razdoblja.

\section{Dino Milinović}

Odsjek za povijest umjetnosti

Filozofski fakultet

Sveučilište u Zagrebu

dmilinov@ffzg.hr

http://orcid.org/oooo-ooo3-4942-6937
I JADRANKA DAMJANOV, Likovna umjetnost I, Zagreb, I973.

2 Tumačenje postmoderne ovisi, dakako, o načinu na koji shvaćamo „modernu” koja joj prethodi. $\mathrm{Na}$ to upozorava, primjerice, JACQUES LE GOFF, La vieille Europe et la nôtre, Paris, I994., 58.

3 Vidi HANS BElting, Das Ende der Kunstgeschichte. Eine Revision nach zehn Jahren, München, 2002. (drugo, prošireno izdanje). 
Moj drugi razlog za današnju temu jest višegodišnji rad na knjizi o nastanku i ikonografiji prve kršćanske umjetnosti koja je izišla iz tiska neposredno prije Kongresa. ${ }^{4} \mathrm{Knjiga} \mathrm{je} \mathrm{moj} \mathrm{poku-}$ šaj sagledavanja velikih promjena koje su zadesile antički svijet i umjetnost između 2. i 5. stoljeća. Zanimljivo je pratiti evoluciju tumačenja tih promjena u povijesti umjetnosti tijekom 2o. stoljeća: 3o-ih godina Rodenwaldt u njima vidi zaokret u stilu (Stilwandel); ${ }^{5}$ polovinom stoljeća, Bianchi Bandinelli krizu helenističke forme objašnjava u duhu marksističke dijalektike (suprotstavljajući patricijsku i plebejsku umjetnost); za Jaśa Elsnera, koji piše potkraj stoljeća, kraj klasične antike i uspon kršćanske kulture samo je posljednja u nizu metamorfoza rimske kulture iznutra. ${ }^{7}$ Od dominantne uloge stila, preko društvene klase, do umjetnosti kao bitnog izraza kulturnog identiteta, možemo pratiti ne samo transformaciju antičkoga svijeta nego i moderne povijesti umjetnosti; Beltingovim riječima, od „samostalne discipline s unutrašnjom strukturom i logikom”, do „discipline koja se razvodnjava u širokom moru kulture i društva".

$\mathrm{Na}$ mnogo načina, sudionici velikih promjena koje su zadesile antičku umjetnost morali su biti $u$ istoj nedoumici kao Hans Belting. Uzmimo, za primjer, reljefe s posljednjega velikog slavoluka podignuta u Rimu 3I5. godine u slavu Konstantinove pobjede. Moderna povijest umjetnosti dugo nije znala kako se postaviti prema tome ključnom spomeniku kasne antike. Alois Riegl je potkraj I9. stoljeća razradio svoj revolucionarni koncept umjetničkoga htijenja (Kunstwollen) upravo proučavajući umjetničku proizvodnju kasne antike, a reljefi Konstantinova friza poslužili su mu kao jedna od njegovih najjasnijih likovnih formulacija (sl. I). Međutim, Riegl spomenik nije mogao
4 DiNo MILINOvić, Nova post vetera coepit. Ikonografija prve kršćanske umjetnosti, Zagreb, 2016.

5 GERHART RODENWALDT, Über den Stilwandel in der antoninischen Kunst, u: Abhandlungen der Preussischen Akademie der Wissenschaften. Philosophisch-historische Klasse, 3 (I935.).

6 RANUCCIO BIANCHI BANDINELLI, Rome, the Centre of Power, London, I970.

7 JAŚ ELSNER, Imperial Rome and Christian Triumph, Oxford-New York, I998.

8 Pritom treba ukazati na razliku među pojedinim nacionalnim školama, pa je tako u francuskoj tradiciji poglavito prisutna tzv. poetika vizualnoga, odnosno, izostala je razlika između povijesti umjetnosti i umjetničke kritike, dobrim dijelom i zbog vrlo kasnih prijevoda temeljnih radova povjesničara umjetnosti s njemačkoga govornog područja; vidi DANIEL LAGOUTTE, Introduction à l'histoire de l'art, Paris, 200I., I5O.

Slika I

Friz na Konstantinovom

slavoluku, 3I5.

foto: G. von Kaschnitz

DAI Rom 3I.2069

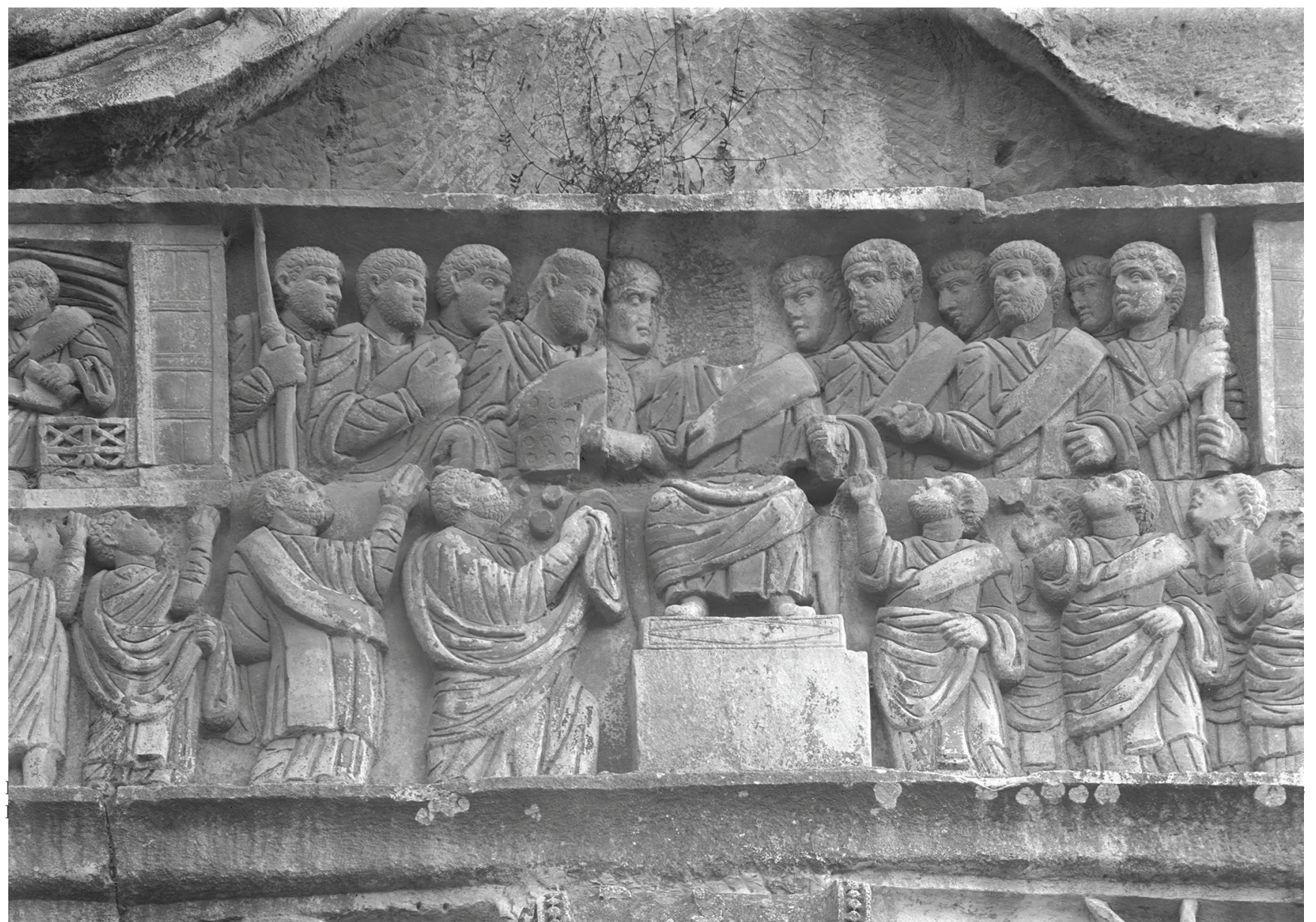


sagledati kao cjelinu, jer bi to narušilo njegovu osnovnu ideju, zasnovanu na kriteriju stila i linearne periodizacije. Tada bi, naime, morao objasniti činjenicu da su na istome slavoluku nanovo upotrijebljeni reljefi iz 2. stoljeća (u rasponu od početka do kraja stoljeća), gotovo dvije stotine godina stariji i stilski znatno drukčiji. To bi, dakako, zahtijevalo dodatna objašnjenja, a možda i napuštanje početne premise.

Za razliku od Riegla, koji je zažmirio na evidentnu činjenicu, veliki renesansni slikar Rafael u pismu papi Lavu X., koji mu je povjerio obnovu spomenika, zabilježio je ono očito: „Skulpture na slavoluku su vrlo slabe i ne pokazuju nikakvo umijeće. No one skulpture koje su plijen s drugih spomenika su izrazito

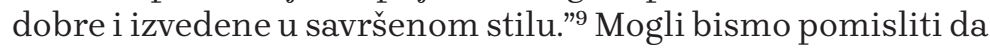
će i Konstantinovi suvremenici prepoznati formalnu razliku među reljefima na slavoluku, komentirati „savršeni stil” onih iz vremena Trajana, Hadrijana ili Marka Aurelija, odnosno „slabu kvalitetu” novijih reljefa. Ali to nije slučaj. Je li formalni aspekt likovnoga djela u njihovim očima bio toliko sporedan da nije zavrijedio komentara? Ili odgovor leži u nepostojanju odgovarajućeg okvira povijesti umjetnosti koji bi obuhvatio fenomen spolije, tako tipične za kasnu antiku, a koji je danas, u eri intertekstualnosti, najzanimljiviji aspekt rimskoga spomenika?

Istina, disciplina povijesti umjetnosti kao takva u antici nije postojala, ali zasigurno smijemo govoriti o „nizu praktično usmjerenih pravila koja su dovela do toga da specifični obrasci likovnog prikaza i figuralni tipovi budu smatrani najboljima za pojedine teme i poruke. Ta su pravila u razmjerno kratku vremenu stekla određenu konzistenciju i koherenciju. U tom smislu, slobodno smijemo govoriti o sustavu."10 Taj je likovno-semantički sustav u vrijeme Rimskoga Carstva počivao na velikim kiparima iz prošlosti. Osim brojnih kopija njihovih najpoznatijih djela, dobar primjer njihova prestiža je Pauzanijin Vodič po Grčkoj iz 2. stoljeća, o kojemu je detaljnije na Kongresu govorio prof. Vladimir Goss. Pauzanija rijetko kada govori o umjetnicima svoga doba. Njegovo je divljenje okrenuto slavnim imenima iz prošlosti; njihova su djela ta zbog kojih ljudi posjećuju hramove, palače i galerije, baš poput turista koji danas pune naše muzeje. Izlošci u imaginarnom muzeju grčkoga putopisca imaju autoritet umjetnosti; ono što je ostalo izvan njega, jednostavno ne pripada u istu kategoriju.

U tako organiziranu sustavu djela Fidije, Polikleta, Praksitela i drugih nisu nositelji samo estetskih nego i etičkih kategorija. Slično McLuhanovoj definiciji medija, stil velikih umjetnika postaje njihova poruka. U svijesti suvremenika ta je forma nositelj značenja kao što su maiestas, gravitas, sanctitas, auctoritas-sve odreda kategorije na kojima počiva rimski sustav vrijednosti. Ali premda još i potkraj 4. stoljeća pojedinci poput Amijana Marcelina veličinu antičke umjetnosti svode na Fidiju i Praksitela, s promjenama koje su zadesile helenističko-rimski svijet u vrijeme kasne antike postupno nestaju i stoljećima usađivana značenja. Klasični je kip prestao biti nositelj poruke i postao suvišan kao medij. Tomu svjedoči nagli pad u broju sačuvanih kopija diljem Carstva tijekom 3. stoljeća, što
9 Vidi E. CAMESASCA i G. PIAZZA (ur.), Raffaello, gli scritti, lettere, firme, sonetti, saggi tecnici e teorici, Biblioteca Universale Rizzoli, Milano, I993., 257 i dalje.

Io TONIO HÖLSCHER, The Language of Images in Roman Art, Cambridge University Press, Cambridge, 2004., I00. 

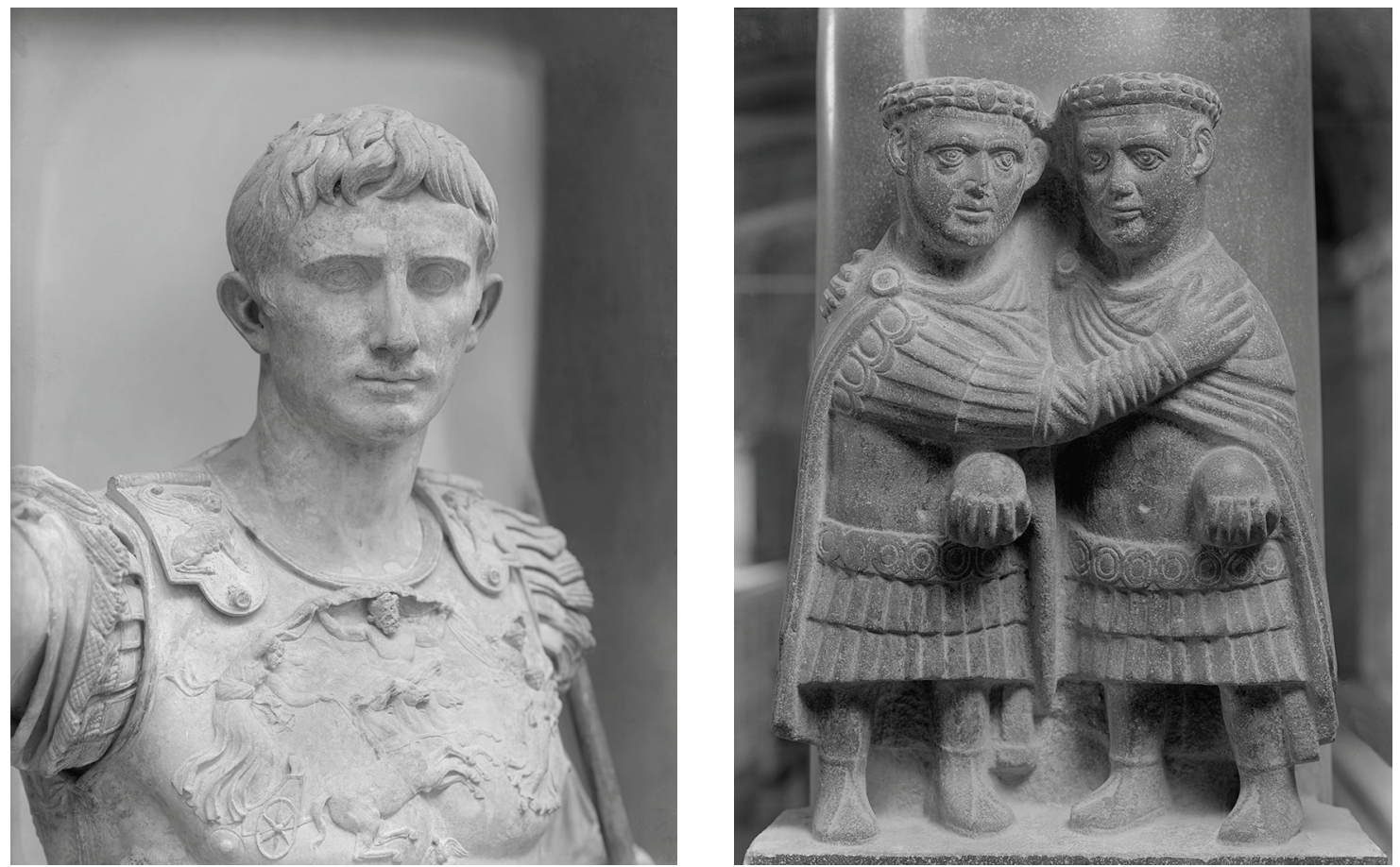

ukazuje na sve manji interes za tu vrstu umjetnosti. ${ }^{11}$ Razlozi nisu samo kultna uloga kipa-što je moglo vrijeđati sve brojnije kršćane (i druge monoteiste)-već i postupni nestanak onih etičkih kategorija koje su bile bitan dio njegova sadržaja.

Ponajbolja ilustracija takvih promjena vidljiva je u prikazu cara, odnosno careva: August Prima Porta (sl. 2) nositelj je političke ikonografije koja je u sprezi sa značenjem klasične forme, na što upućuje namjerno korištenje Polikletova Dorifora za uzor. U očima suvremenika, ta je forma (stil) povezana s vrijednostima koje su se tradicionalno vezivale uz bogove i careve; odgovarajući epiteti su veličanstven, ozbiljan, svet, pobožan i slično, a isti se ponavljaju i u službenim carskim titulama. S druge strane, tetrarsi iz Vatikanske biblioteke u Rimu s kraja 3. stoljeća (sl. 3), koriste sasvim drukčiji likovni jezik. On je u toj mjeri lišen klasičnih reminiscencija da smijemo govoriti o antiklasičnim tendencijama. Poruka tih slika je nešto sasvim drugo; ona je brutalno jednostavna, kao što je to i karakter (i podrijetlo) ovih careva. Hans Peter L'Orange govori o zastrašujućim slikama (Schreckbilder). ${ }^{12}$ Možda su i one utjecale na nepovoljan sud suvremenika: kršćanin Laktancije omraženome tetrarhu Galeriju pripisuje mržnju ne samo prema kršćanima nego prema svemu što je rimsko. ${ }^{13}$ Prema Laktanciju, upravo je kršćanski Bog, uz Konstantinovu pomoć, osujetio njegov barbarski plan i pomogao obnoviti republiku tradicionalnih vrijednosti. Nije čudo da je lice kršćanskoga šampiona označilo povratak na klasični stilski izraz Augustova doba (sl. 4). Ipak, sve te brze i drastične formalne promjene-Robert Smith govori o "stilskom kaosu"-nisu ostavile traga u zapisima suvremenika. ${ }^{14}$ Suvremena produkcija nije imala pristupa $u$

II Ekonomska kriza je samo dio mogućeg objašnjenja za nestanak klasičnoga kipa; vidi, primjerice, DINO MILINOVIĆ (bilj. 4), 77 i dalje.

I2 HANS PETER L'ORANGE, Das spätantike Herrscherbild von Diokletian bis zu den Konstantin-Söhnen, Berlin, ı984., 66.

I3 To je neprijateljstvo išlo tako daleko da je namjeravao promijeniti ime Carstvu u Dačko Carstvo; LAKTANCIJE, O smrtima progonitelja, 27, 8. 


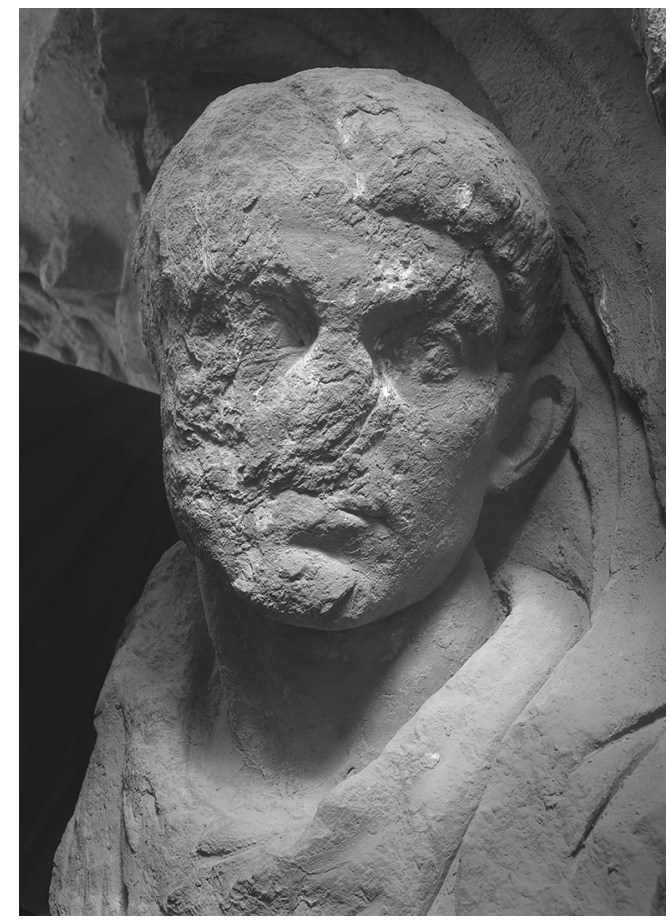

ljubomorno čuvan svijet antičkoga muzeja, odnosno ostala je izvan sustava koji je antika stvorila kao okvir za razmišljanje o umjetnosti.

* Smijem li iskoristiti ovih nekoliko primjera i postaviti pitanje određene sličnosti između „kraja povijesti umjetnosti” u razdoblju kasne antike (koje Winckelmann naziva „dobom oponašatelja”) i današnjega trenutka naše discipline? Paradigma slike u naše doba također se promijenila, i nastavlja se brzo mijenjati. Ne govorimo više o postmoderni, već, kako kaže Belting, o postljudskome (post-human). ${ }^{15}$ Tradicionalni okvir povijesti umjetnosti nije više u mogućnosti odgovoriti na promjene koje su nas zadesile, niti im se institucija muzeja-koji je podrijetlom pravi blizanac naše discipline-može tako brzo prilagoditi. Reljefi Konstantinova slavoluka, ona skulptura koju Rafael opisuje kao „vrlo slabu”, čekali su punih petnaest stoljeća na primjereno tumačenje, sve do Aloisa Riegla. Čini se da je povijest umjetnosti i dalje nedovršena priča. U tom smislu, umjesto da govorimo o njezinu kraju, trebali bismo postaviti pitanje: što nam je promaknulo?

\section{(ㄷ) (i)}

Pitanje stila i problemi periodizacije: nedovršeni posao povjesničara umjetnosti (2. dio)/Dino Milinović / CC BY / 4.o

DOI: https://doi.org/ıo.3ı664/z4khpu.I3

I4 ROBERT R. R. SMITH, The Public Image of Licinius I: Portrait Sculpture and Imperial Ideology in the Early Fourth Century, u: The Journal of Roman Studies, 87 (I997.), I84.

I5 HANS BELTING (bilj. 3), I9. 